\title{
Neuromuscular blockade in clinical practice in paediatric anaesthesia: retrospective cohort trial in a tertiary paediatric anaesthesia centre
}

\author{
JOZEF KLUČKA ${ }^{1}$, MICHAELA ŤOUKALKOVÁ ${ }^{1}$, IVO KĽIKAVA ${ }^{1}$, ROMAN ŠTOUDEK ${ }^{1}$, \\ EVA KLABUSAYOVÁ ${ }^{2}$ MÁRIA MORAVSKÁ ${ }^{2}$ PETR ŠTOURAČ ${ }^{1}$ \\ ${ }^{1}$ Department of Paediatric Anaesthesiology and Intensive Care Medicine, University Hospital \\ Brno, Faculty of Medicine, Masaryk University, Brno, Czech Republic \\ ${ }^{2}$ Faculty of Medicine, Masaryk University, Brno, Czech Republic
}

Corresponding author:

Petr Štourač

Department of Paediatric Anaesthesiology and Intensive Care Medicine

University Hospital Brno

Jihlavska 20, Brno, 62500 Czech Republic

Phone: +420532234261

E-mail:petr.stourac@gmail.com

\section{ABSTRACT}

Background. Neuromuscular blockade is associated with improved airway conditions for intubation and superior conditions for surgical interventions (predominantly important in laparoscopic surgery). Residual neuromuscular blockade in the postoperative period is, according to recently published data, associated with a negative impact on perioperative morbidity and mortality.

Aim. The aim of the study was to describe daily practice in clinical paediatric anaesthesia in a tertiary children's hospital.

Methods. Data from anaesthesiology records during the period 1.1.2016 to 31.12.2016 were retrospectively screened. Primary outcomes included the rate of surgery cases with neuromuscular blockade, the incidence of cases with perioperative neuromuscular blockade monitoring and the incidence of neuromuscular pharmacologic block reversal. Secondary outcomes were myorelaxant usage according to the age of patients and duration of surgery.

Results. Overall 8046 paediatric patients underwent general anaesthesia in the study period. Muscle relaxants were administered in 1650 cases $(20.5 \%)$. The most frequently administered muscle relaxant was mivacurium (48.2\%, $\mathrm{n}=795)$, followed by cis-atracurium $(36.4 \%, \mathrm{n}=601)$, suxamethonium $(10.3 \%, \mathrm{n}=170)$ and rocuronium $(7.0 \%, \mathrm{n}=115)$. Neuromuscular blockade monitoring was used only in $2.5 \%(n=41)$ of cases. Active neuromuscular blockade reversal was administered in 5.8\% $(\mathrm{n}=95)$ of cases.
Conclusion. Neuromuscular blockade in paediatric anaesthesia was less frequent compared to adults. The low rate of neuromuscular blockade monitoring in combination with the low rate of active block reversal can be considered dangerous due to the relatively high risk of potential residual postoperative blockade, that can negatively influence clinical outcome.

Key words: neuromuscular blocking agent, paediatric anaesthesia, residual blockade, neuromuscular blockade

\section{INTRODUCTION}

Neuromuscular blockade (NB) can be considered a standard part of general anaesthesia. NB is associated with improved intubation conditions, reduced airwayassociated complications (1) and has led to development of special surgery techniques, including laparoscopy (NB improved surgical conditions). (2) Recommended dosing of muscle relaxants can be considered as only informative, according to the high variable duration of effect. (3) At the end of surgery, it is highly advisable to objectively measure the neuromuscular blockade to exclude potential residual blockade (RB). Complete recovery is a mandatory requirement for safe anaesthesiology practice. $\mathrm{RB}$ in the postoperative period remains a widely debated problem of daily practice in anaesthesiology, although very trivialized in the paediatric subpopulation. There is a strong and clear connection between $\mathrm{RB}$ and the negative impact on mortality and morbidity in postoperative period (regurgitation, silent aspiration, hypoxia, upper airway obstruction, pneumonia and patient discomfort) (4) and, if not treated, can lead to fatal consequences. Clinical signs of recovery (squeezing of the hand, lifting the head and other signs) are not sufficiently sensitive compared to accelerometry (5) and require the patient's active involvement, which can be difficult and is influenced by the age of the patient. Although, it seems, that the usage of NB in paediatric anaesthesia is lower (compared to adults), the incidence of active pharmacological reversal of blockade and the incidence of neuromuscular blockade monitoring remains unclear. The aim of this study was to describe the actual practice in a tertiary paediatric anaesthesiology centre - incidence of NB usage, incidence of monitoring the depth of blockade and possible RB at the end of surgery and incidence of active pharmacological reversal.

\section{MATERIALS AND METHODS}

The retrospective cohort study was approved by the local Ethics Committee of the University Hospital Brno and the trial was registered on www.clinicaltrials.gov (ClinicalTrials.gov Identifier: NCT03086915). All paediatric patients who underwent general anaesthesia at the Department of Paediatric Anaesthesiology and Intensive Care Medicine during the study period between 1. 1. 2016 and 1. 12. 2016, based on data derived from anaesthesiology records, were screened. Anaesthesiology cases with muscle relaxant usage were included in the analysis. Methods of descriptive statistics (incidence, mean, median) were used for 
study group data (tables 1-4). The primary outcome was the frequency of neuromuscular blockade monitoring and the incidence of active pharmacological block reversal at the end of the operation. The secondary outcome was the frequency of different muscle relaxant usage according to the age of the patients and duration of surgery. Kruskal-Wallis $\mathrm{H}$ test was used to analyse the statistical significance by using the median values and Chi-squared test by using the average values (tables 2, 3). Pearson Chi-squared test was used to analyse the differences between types of surgery and patients with active block reversal (table 4). Software SPSS 23 (IBM, USA) was used for statistical analysis.

\section{RESULTS}

After initial screening, 8046 paediatric patients underwent surgery under general anaesthesia in the study period. The rate of cases with NB was $20.9 \%(n=1685)$. After exclusion of $17(0.2 \%)$ patients due to insufficient anaesthesiology records and 18 $(0.2 \%)$ due to age limit (age over 19 years), $1650(20.5 \%)$ patients were included in the analysis. The median age of the cohort was 11 years ( 1 day - 19 years). The demographic data are summarized in the table 1. Neuromuscular blockade monitoring (accelerometry, TOF-Watch SX) was used in $2.5 \%(n=41)$ of cases. From the whole cohort $(n=1650)$, active pharmacological reversal of the blockade was administered in $5.8 \%(n=95)$ of cases. The drug used for block reversal was neostigmine in $71.6 \%$ $(\mathrm{n}=68)$ and sugammadex in $28.4 \%(\mathrm{n}=27)$ of cases with active block reversal. The duration of surgery was comparable between groups with neostigmine reversal, sugammadex reversal or non-reversal (median duration - $70 \mathrm{~min}$ vs. $70 \mathrm{~min}$ vs. $70 \mathrm{~min}$, $\mathrm{p}=0.4096$ ). Neuromuscular blockade was significantly more frequently antagonized in older patients (median age in years - 13 vs. 14 vs. $10, p=p<0.001$ ) (for detailed description see table 2 ). In 16 cases (23.5\%), neostigmine was administered without atropine (anticholinergic drug given to suppress the negative cholinergic stimulation induced by neostigmine), the only intravenous anticholinergic agent available in the Czech Republic. The most frequently administered MR was mivacurium (48.2\%), followed by cis-atracurium (36.4\%) and suxamethonium (10.3\%). Neuromuscular blockade was most frequently antagonized after rocuronium administration (32 patients of $115-27.8 \%)$. The longest mean surgery duration time was in patients in

Table 1. Age, weight and duration of surgery in patients with muscle relaxation

\begin{tabular}{llll}
\hline & Weight $($ in $\mathbf{~ k g})$ & Age (in years) & Surgery duration (in minutes) \\
\hline Average & $39.2(0.8-121)$ & $10.0(0-19)$ & $88.0(10-655)$ \\
\hline Median & 36.3 & 11 & 70 \\
\hline
\end{tabular}

Table 2. Age, duration of surgery in patients with active blockade reversal and in patients without active reversal

\begin{tabular}{lllll}
\hline & Neostigmine & Sugammadex & Without active reversal & p value \\
\hline Number of patients & $68(4.1 \%)$ & $27(1.6 \%)$ & $1555(94.2 \%)$ & - \\
\hline Age (in years) average & $12.8(1-19)$ & $13.6(6-19)$ & $9.8(0-19)$ & $\mathrm{p}<0.001$ \\
\hline $\begin{array}{l}\text { Age (in years) } \\
\text { median }\end{array}$ & 13 & 14 & 10 & $\mathrm{p}<0.001$ \\
\hline $\begin{array}{l}\text { Surgery duration } \\
\text { (in minutes) average }\end{array}$ & $84.7(30-300)$ & $82.3(25-170)$ & $87.9(10-655)$ & $\mathrm{p}=0.9744$ \\
$\begin{array}{l}\text { Surgery duration (in } \\
\text { minutes) median }\end{array}$ & 70 & 70 & 70 & $\mathrm{p}=0.4096$ \\
\hline
\end{tabular}

the cis-atracurium subgroup (116 minutes, 15-380 minutes, $\mathrm{p}<0.001)$ followed by the rocuronium subgroup of patients (94 minutes, 25-315 minutes, $\mathrm{p}<0.001$ ) and the shortest mean surgery duration time was detected in atracurium subgroup (66 minutes, 30-150 minutes, $\mathrm{p}<0.001)$ followed by mivacurium subgroup (70 minutes, 10-655 minutes, $\mathrm{p}<0.001$ ) (table 3).

The patients in our cohort were predominantly general surgical patients $(42.0 \%$, $\mathrm{n}=693)$, ENT patients $(26.9 \%, \mathrm{n}=445)$ and orthopaedic patients $(14.7 \%, \mathrm{n}=242)$. According to the type of surgical intervention, active reversal was most frequently administered in the subgroup of general surgery patients $(8.2 \%, \mathrm{n}=57)$, which represents $60.0 \%$ of all patients with active block reversal. The highest rate of reversal was detected in the laparoscopic surgery subgroup (active reversal rate $21.1 \%$ $(39 / 185, \mathrm{p}<0.001)($ table 4).

\section{DISCUSSION}

The most important finding was a low rate of neuromuscular blockade monitoring (2.5\%). It can be considered very low when compared to data from the adult population, where the reported rate is up to $24.4 \%$. (6) Due to the high risk of RB in the postoperative period in adults and the paediatric population too, $(7,8)$ the absence of monitoring with the combination of a low rate of active block reversal (5.8\% in the study) can be considered risky. Neuromuscular blockade monitoring implementation in daily practice (from $2 \%$ to $60 \%$ of cases) has led (in the adult population) to a rapid increase in active block reversal fre- quency (from $6 \%$ to $42 \%$ ). $(9,10)$ The low documented rate of blockade monitoring can be partially explained by the design of anaesthesiology records (no predefined section for TOF measurement) and the low number of TOF-Watch monitors available on the anaesthesiology department (at the study period only 2 monitors were available). The blockade induced by mivacurium was antagonized in 8 cases ( $1.0 \%$ of mivacurium group) - in all cases with neostigmine, although neostigmine can inhibit plasma cholinesterase and by doing so slow down mivacurium metabolism in the plasma. (11) According to the manufacturer, the effect of mivacurium lasts for 13-23 minutes. Due to its unique metabolism (by plasma cholinesterase) there can be a higher risk of blockade prolongation and residual blockade in patients with liver dysfunction, kidney dysfunction and in elderly patients. The highest risk of prolonged blockade is in patients with the mutation of the gene for plasma cholinesterase, where in heterozygous individuals (prevalence in the population 1-3/1000) it can be prolonged by $50 \%$ and even more significantly in homozygous individuals. $(12,13)$ Neuromuscular blockade monitoring is therefore meaningful also in cases where short- or intermediate-acting muscle relaxants have been used, because early recognition and RB reversal can positively influence the overall outcome. Patients extubated at the end of surgery with $\mathrm{RB}$, defined as $\operatorname{TOFr}<0.9$, have higher documented postoperative morbidity and mortality. Implementing monitoring of neuromuscular blockade into routine practice can lead to early recognition of patients at risk and subsequently select patients who 
Table 3. Block reversal, duration of surgery and age according to muscle relaxant

\begin{tabular}{|c|c|c|c|c|c|c|}
\hline & Mivacurium & Cis-atracurium & Rocuronium & Suxamethonium & Atracurium & p value \\
\hline Number of patients & $795(48.2 \%)$ & $601(36.4 \%)$ & $115(7.0 \%)$ & $170(10.3 \%)$ & $18(1.1 \%)$ & $\mathrm{p}<0.001$ \\
\hline $\begin{array}{l}\text { Number of patients with } \\
\text { block reversal }\end{array}$ & $8(1.0 \%)$ & $53(8.8 \%)$ & $32(27.8 \%)$ & $0(0 \%)$ & $2(11.1 \%)$ & $\mathrm{p}<0.001$ \\
\hline Age (in years) average & $10.4(0-19)$ & $9.8(0-19)$ & $11.3(0-19)$ & $7.2(0-19)$ & $12.2(0-17)$ & - \\
\hline $\begin{array}{l}\text { Age (in years) } \\
\text { median }\end{array}$ & 11 & 11 & 12 & 6 & 13.5 & - \\
\hline $\begin{array}{l}\text { Surgery duration (in } \\
\text { minutes) } \\
\text { average }\end{array}$ & $\begin{array}{l}69.8 \\
(10-655)\end{array}$ & $\begin{array}{l}116.1 \\
(15-380)\end{array}$ & $\begin{array}{l}94.1 \\
(25-315)\end{array}$ & $\begin{array}{l}71.6 \\
(15-250)\end{array}$ & $\begin{array}{l}65.8 \\
(30-150)\end{array}$ & $\mathrm{p}<0.001$ \\
\hline $\begin{array}{l}\text { Surgery duration (in } \\
\text { minutes) } \\
\text { median }\end{array}$ & 60 & 105 & 80 & 60 & 60 & $\mathrm{p}<0.001$ \\
\hline
\end{tabular}

Table 4. Neuromuscular blockade reversal according to the type of surgery

\begin{tabular}{|c|c|c|c|c|c|c|c|c|c|}
\hline Type of surgery & ENT & $\begin{array}{l}\text { Plastic } \\
\text { surgery }\end{array}$ & Ophtalmology & $\begin{array}{l}\text { General } \\
\text { surgery } \\
\text { (without } \\
\text { laparoscopy) }\end{array}$ & $\begin{array}{l}\text { Laparoscopy } \\
\text { (general } \\
\text { surgery) }\end{array}$ & $\begin{array}{l}\text { Dental } \\
\text { surgery }\end{array}$ & $\begin{array}{l}\text { Orthopaedic } \\
\text { surgery }\end{array}$ & Neurosurgery & Radiology \\
\hline Number of patients & $\begin{array}{l}26.9 \% \\
(n=445)\end{array}$ & $\begin{array}{l}3.7 \% \\
(n=61)\end{array}$ & $\begin{array}{l}3.45 \% \\
(n=57)\end{array}$ & $\begin{array}{l}30.7 \% \\
(n=508)\end{array}$ & $\begin{array}{l}11.2 \% \\
(n=185)\end{array}$ & $\begin{array}{l}2.3 \% \\
(n=38)\end{array}$ & $\begin{array}{l}14.6 \% \\
(n=242)\end{array}$ & $5.2 \%(\mathrm{n}=86)$ & $1.7 \%(\mathrm{n}=28)$ \\
\hline $\begin{array}{l}\text { Number of patients } \\
\text { with active reversal } \\
\text { according to the type } \\
\text { of surgery }\end{array}$ & $\begin{array}{l}2.4 \% \\
(\mathrm{n}=11)\end{array}$ & $\begin{array}{l}3.2 \% \\
(n=2)\end{array}$ & $\begin{array}{l}1.7 \% \\
(\mathrm{n}=1)\end{array}$ & $\begin{array}{l}5.5 \% \\
(n=28)\end{array}$ & $\begin{array}{l}21.0 \% \\
(\mathrm{n}=39)\end{array}$ & $\begin{array}{l}2.6 \% \\
(n=1)\end{array}$ & $\begin{array}{l}4.1 \% \\
(n=10)\end{array}$ & $3.4 \%(n=3)$ & $0.0 \%(\mathrm{n}=0)$ \\
\hline
\end{tabular}

benefit the most from active block reversal. Currently there are two drugs designated for neuromuscular blockade reversal: neostigmine (Syntostigmin ${ }^{\circledR}$ ) and sugammadex $\left(\right.$ Bridion $\left.^{\otimes}\right)$. Sugammadex is a specific gama-cyklodextrine, that acts through encapsulation of the free plasmatic fraction of aminosteroids (rocuronium, vecuronium). According to the manufacturer, it is currently approved for use in patients over 2 years of age. The dosage depends on the depth of the RB (2mg/kg if TOF $1-2,4 \mathrm{mg}$ if PTC - post-tetanic count 1-2). Only sugammadex is capable of fully reversing deep neuromuscular blockade, in the case of a failed airway (dose needed for complete reversal $-16 \mathrm{mg} / \mathrm{kg}$ ). This technique is not recommended in paediatric patients due to lack of data, however it can be lifesaving in an urgent situation. Neostigmine, as the second drug of choice for block reversal, acts as a reversible inhibitor of acetylcholinesterase and reinforces the effect of acetylcholine on nicotinic and muscarinic receptors. Due to the mechanism of the drug, neostigmine administration, without anticholinergic medication (atropine) co-administration, can be considered dan- gerous. The main neostigmine limitation is that it has the capability of reversing only shallow blockade (TOF 1-2) but it acts on both - aminosteroids (rocuronium, vecuronium) and bensylisoquinolines (atracurium, cis-atracurium). However, the effect has a slow onset and a ceiling effect. Neostigmine administration to patients with a deep blockade (TOF囚1) can lead to paradoxical deepening of the blockade. The low rate of neuromuscular blockade monitoring at the end of surgery may have been influenced by the retrospective design of the study and insufficient documentation. These results point to the several clinical problems - neuromuscular blockade reversal with neostigmine without an anticholinergic agent, active reversal of neuromuscular blockade induced by mivacurium with neostigmine and the low rate of neuromuscular blockade.

\section{CONCLUSION}

The low incidence of active block reversal can be considered dangerous, due to the high risk of RB. $(7,9,14)$ It is highly recom- mended to monitor the depth of neuromuscular blockade in all patients in whom muscle relaxants have been administered, in agreement with a recently published national statement for safe anaesthesia practice by Czech Society of Anaesthesiology and Intensive Care Medicine (published on 8th April 2017).

\section{FUNDING}

The article was published with $\mathrm{t}$ support from the Masaryk University Brno, Czech Republic - MUNI/A/1161/2016 and with non-financial support from University hospital Brno, Czech Republic.

\section{ACKNOWLEDGEMENT}

Preliminary results of this article were presented at Student Scientific Conference 2017 of Medical Faculty of Masaryk University, Brno, Czech Republic and the presentation was awarded 2 th place in the Surgical Section. 
1. Julien-Marsollier, F, Michelet, D, Bellon, M, Horlin, AL, Devys, JM, Dahmani, S. Muscle relaxation for tracheal intubation during paediatric anaesthesia: a meta-analysis and trial sequential analysis. Eur J Anaesthesiol. 2017 Aug;34(8):550-561.

2. Blobner M, Frick CG, Stäuble RB, Feussner H, Schaller SJ, Unterbuchner C, et al. Neuromuscular blockade improves surgical conditions (NISCO). Surg Endosc 2015 Mar;29(3):627-36.

3. Brandom BW, Meretoja OA, Simhi E, Taivainen T, Wolfe SR, Woelfel SK, et al. Age related variability in the effects of mivacurium in paediatric surgical patients. Can J Anaesth 1998 May;45(5 Pt 1):410-6.

4. Murphy GS, Szokol JW, Marymont JH, Greenberg SB, Avram MJ, Vender JS. Residual neuromuscular blockade and critical respiratory events in the postanesthesia care unit. Anesth Analg 2008 Jul;107(1):130-7.

5. Brull SJ, Murphy GS. Residual neuromuscular block: lessons unlearned. Part II: methods to reduce the risk of residual weakness. Anesth Analg 2010 Jul;111(1):129-40.

6. Naguib M, Kopman AF, Ensor JE. Neuromuscular monitoring and postoperative residual curarisation: a meta-analysis. Br J Anaesth 2007 Mar;98(3):302-16.

7. Murphy GS, Szokol JW, Marymont JH, Franklin M, Avram MJ, Vender JS. Residual paralysis at the time of tracheal extubation. Anesth Analg 2005 Jun;100(6):1840-5.

8. Esteves S, Martins M, Barros F, Barros F, Canas M, Vitor P, et al. Incidence of postoperative residual neuromuscular blockade in the postanaesthesia care unit: an observational multicentre study in Portugal. Eur J Anaesthesiol 2013 May;30(5):243-9.

9. Baillard C, Clec'h C, Catineau J, Salhi F, Gehan G, Cupa M, et al. Postoperative residual neuromuscular block: a survey of management. Br J Anaesth 2005 Nov;95(5):622-6.

10. Baillard C, Gehan G, Reboul-Marty J, Larmignat P, Samama CM, Cupa M. Residual curarization in the recovery room after vecuronium. Br J Anaesth 2000 Mar;84(3):394-5.

11. Bevan JC, Tousignant C, Stephenson C, Blackman L, Reimer E, Smith MF, et al. Dose responses for neostigmine and edrophonium as antagonists of mivacurium in adults and children. Anesthesiology 1996 Feb;84(2):354-61.

12. Naguib M, el-Gammal M, Daoud W, Ammar A, Moukhtar H, Turkistani A. Human plasma cholinesterase for antagonism of prolonged mivacurium-induced neuromuscular blockade. Anesthesiology 1995 May;82(5):1288-92.

13. Davis L, Britten JJ, Morgan M. Cholinesterase. Its significance in anaesthetic practice. Anaesthesia 1997 Mar;52(3):244-60.

14. Kopman AF. Undetected residual neuromuscular block has consequences. Anesthesiology 2008 Sep;109(3):363-4. 